\title{
Apontamentos sobre a Tessitura de Redes como Perspectiva Contemporânea da Pesquisa no Campo da Educação
}

\author{
ISABEL MARIA SABINO DE FARIAS \\ Pedagoga (UECE). Doutora em Educação Brasileira (UFC), com Estágio Pós-Doutoral pela \\ Universidade de Brasília (UnB). Professora do Centro de Educação e do Programa de Pós- \\ Graduação em Educação (PPGE) da Universidade Estadual do Ceará (UECE). Líder do grupo \\ de pesquisa Educação, Cultura Escolar e Sociedade (EDUCAS/CNPq). Coordenadora do \\ Observatório Desenvolvimento Profissional Docente e Inovação Pedagógica. ORCID: https:// \\ orcid.org/0000-0003-1799-0963 E-mail: isabel.sabino@uece.br
}

\begin{abstract}
RESUMO
Este escrito apresenta apontamentos acerca da tessitura de redes como tendência no campo da pesquisa, em particular na pesquisa em Educação, estratégia de ampliação do processo associativo de pesquisadores no delineamento de alternativas para a melhoria da qualidade do conhecimento, consequentemente para seu avanço. Inicia retomando aspectos históricos da gênese da pesquisa em Educação na cena nacional, reflexão entremeada por anotações buscando explicitar a perspectiva dominante nesse percurso. Registra, em seguida, experiência de pesquisa em rede empreendida pela articulação de quatro Programas de Pós-graduação em educação de três Universidades públicas situadas nas regiões Nordeste e Sudeste do país, iniciativa apoiada pelo Programa Observatório da Educação (OBEDUC), promovido pela CAPES.
\end{abstract}


Apontamentos sobre o contributo da formação pós-graduada stricto sensu encerram as reflexões em torno do potencial de processos associativo de pesquisadores mediante a constituição de redes.

Palavras-chave: Pesquisa em rede. Tendência de pesquisa. Pesquisa em Educação. Formação de pesquisadores.

\section{OBSERVATIONS ON THE COMPOSITION OF NETWORKS AS A CONTEMPORARY PERSPECTIVE OF RESEARCH IN THE FIELD OF EDUCATION}

This paper presents observations about the composition of networks as a trend in the field of research, in particular in the research in Education, strategy to expand the associative process of researchers in the delimitation of alternatives for the improvement of the quality of knowledge, consequently for its advancement. It begins resuming historical aspects of the genesis of Education research in the national scene, and then recording the experience of network research undertaken by the articulation of four post-graduate programs in education of three public universities located in the Northeast and Southeast regions of the country, project supported by the Education Observatory Program (OBEDUC) promoted by CAPES. Observations on the contribution of postgraduate stricto sensu formation conclude the reflections about the potential of associative processes of researchers through the creation of networks.

Key words: Network Research. Research Trend. Research in Education. Researchers Formation.

\section{OBSERVACIONES SOBRE LA COMPOSICÍON DE REDES COMO PERSPECTIVA CONTEMPORÁNEA DE LA INVESTIGACIÓN EN EL CAMPO DE LA EDUCACIÓN}

Este escrito presenta apuntes a cerca de la tesitura de redes como tendencia en el campo de investigación, en particular en la investigación en Educación, estrategia de ampliación del proceso asociativo de investigadores en el delineamiento de alternativas para la mejora de la calidad del conocimiento, consecuentemente, para su avance. Empieza anudando aspectos históricos de la génesis de investigación en Educación en la escena nacional, reflexión entre mezclada por anotaciones buscando explicitar la perspectiva dominante en este recorrido. Registra, en seguida, experiencia de investigación en red emprendida por la articulación de cuatro programas de posgrado en Educación de tres universidades públicas ubicadas en las regiones del Nordeste y Sudeste del país, iniciativa apoyada por el Programa Observatório de Educação (OBEDUC), promovido por la CAPES. Apuntes sobre la contribución de la formación posgraduada stricto sensu encierran las reflexiones en torno al potencial de procesos asociativo de investigadores mediante la creación de redes.

Palabras claves: Investigación en red. Tendencia de investigación. Investigación en Educación. Formación de investigadores. 


\section{Apontamentos sobre a Tessitura de Redes como Perspectiva Contemporânea da Pesquisa no Campo da Educação}

A produção de conhecimento sobre educação no Brasil é relativamente nova, embora a trajetória histórica da emergência da preocupação científica com as questões da área denote vigor e movimento ascendente de consolidação. Neste escrito apresentamos apontamentos acerca da tessitura de redes como tendência no campo da pesquisa, em particular na pesquisa em Educação, estratégia de ampliação do processo associativo de pesquisadores no delineamento de alternativas para a melhoria da qualidade do conhecimento, consequentemente para seu avanço.

Iniciamos essa conversa retomando aspectos históricos da gênese da pesquisa em Educação na cena nacional, reflexão entremeada por anotações buscando explicitar a perspectiva dominante nesse percurso. Tais apontamentos são destacados como necessárias a todo e qualquer exercício de compreensão de perspectivas da pesquisa no campo da Educação. Na sequência, registramos experiência de pesquisa em rede empreendida pela articulação de quatro programas de pósgraduação em educação de três universidades públicas situadas nas regiões Nordeste e Sudeste do país, iniciativa apoiada pelo Programa Observatório da Educação (OBEDUC) promovido pela CAPES. Apontamentos sobre o contributo da formação pós-graduada stricto sensu encerram as reflexões em torno do potencial de processos associativo de pesquisadores mediante a constituição de redes.

\section{Marcos da pesquisa brasileira em Educação}

Como assinalado, o Brasil acumula uma trajetória jovem na produção da pesquisa em Educação (ANDRÉ, 2006), desenvolvimento marcado por traços que, de certo modo, delineiam a orientação assumida, aqui entendida como perspectiva.

A existência de produções esparsas desde as primeiras décadas do século passado são destacadas por Gatti (2002) como indícios da gênese de "certa preocupação científica" com questões educacionais, história que se funde tanto com a constituição da universidade brasileira quanto dos estudos pós-graduados no país. É o que se pode depreender do registro de Balbachesvk (2005, p. 276) ao situar que a origem da pós-graduação brasileira remonta ao "modelo das cátedras adotado nas primeiras universidades brasileiras criadas nos anos 1930", evidenciando clara influência europeia. 
No sistema de cátedra, que no Brasil foi substituído pelo regime departamental de inspiração norte-americana a partir da Reforma Universitária de 1968, as decisões relativas ao ensino, pesquisa e extensão em um dado campo de estudo é responsabilidade de um único professor. Sobre o modelo de cátedra na formação pós-graduada a autora informa ainda:

O elemento central desse modelo era a relação tutorial que se estabelece entre o professor catedrático e um pequeno grupo de discípulo, os quais também atuavam como auxiliares do professor nas atividades de ensino e/ou pesquisa. Nesse formato, [...] a autoridade acadêmica do professor era absoluta: apenas a ele cabia estabelecer o conteúdo e o volume das atividades acadêmicas a serem cumpridas pelos candidatos antes da defesa [...]. Da mesma forma, era esse professor quem determinava quais questões e métodos de demonstração eram aceitáveis para uma dissertação e quais técnicas eram admissíveis para a pesquisa. (BALBACHESVK, 2005, p. 277).

Esse modelo de estudos pós-graduados teve reduzida repercussão no ensino superior brasileiro, uma ação localizada, pois poucas universidades ofereciam esse tipo de formação, além de ser restrita a algumas áreas de conhecimento. A demanda concentrava-se nos interessados em ingressar na vida acadêmica, sendo uma titulação pouco conhecida. "Até então não se falava em pesquisa educacional no país", anota Ferreira (2009, p. 46).

Com efeito, a preocupação com a pesquisa em educação enquanto objeto de política pública se delineia com a criação do INEP (Instituto Nacional de Estudos e Pesquisas Educacionais) (1938), ligado ao MEC, que, naquele momento, entendia a pesquisa como recurso instrumental para a formulação e avaliação de ações oficiais no campo da educação escolar (ANDRÉ, 2006). Esse primeiro momento da pesquisa educacional, que vai de 1940 a 1955,

[...] é caracterizado pela leitura psicológica do processo de educação escolar, com forte influência dos estudos da psicologia do ensino e da aprendizagem e a criação de instrumentos de avaliação psicológica e pedagógica do aluno. As idéias pedagógicas eram marcadas pelo escolanovismo, que fundamentado na pedagogia científica, na biologia e na psicologia defendia o ensino centrado no aluno e valorizava o aprender a aprender. A estrutura inicial do INEP incluía uma Divisão de Psicologia Aplicada que foi criada por influência de Lourenço Filho, psicólogo e defensor das idéias escolanovistas, que foi seu primeiro diretor. Em 1944 começa a ser publicada a Revista Brasileira de Estudos Pedagógicos do INEP, que abriu espaço para divulgação dos trabalhos científicos da área. (ANDRÉ, 2006, p. 13). 
A pesquisa nacional em educação, como revela a autora supracitada, começa e ganha sistematicidade pela ação indutora do Poder Público, que então se configura como principal protagonista dessa oferta.

Este protagonismo, anota André (2006), se firma no período de 1956 a 1964 com a criação do Centro Brasileiro de Pesquisa Educacional e de cinco Centros Regionais de Pesquisa, ligados ao INEP, que se encarregam da formação de pesquisadores no país, uma vez que a universidade assume papel secundarizado nessa tarefa. Nesse momento da trajetória da pesquisa em educação o interesse é "mapear a sociedade brasileira de modo a fornecer dados a uma política educacional que alavancasse o progresso econômico do país, levando em conta as diferenças regionais", registra André (2006, p. 13) referenciando-se nos estudos de Angelucci e outros (2004, p. 54), que por sua vez advertem ser esse um momento de ascensão "das ciências sociais, em chave teórica funcionalista".

O reconhecimento da formação pós-graduada é regulamentado em 1965 quando o Ministério da Educação reconhece-a como um nível de ensino, além do bacharelado. Regulamentação registrada no Parecer n $n^{\circ} 977$ do Conselho Federal de Educação (CEF), também conhecido como Parecer Sucupira. Este parecer estabeleceu "o formato institucional básico da pós-graduação brasileira, diferenciando dois níveis de formação, o mestrado e o doutorado", bem como definiu "uma linha de continuidade entre os dois, consagrando o mestrado como um pré-requisito para o doutorado" (BALBACHESVK, 2005, p. 277).

A primeira regulamentação da pós-graduação brasileira, ainda conforme Elizabeth Balbachevsky, acontece sob os auspícios de "um regime militar com forte orientação nacionalista" e que considerava a educação como fator de desenvolvimento econômico, na perspectiva da teoria do capital humano. Assim, entre os anos de 1965 a 1970, movida, sobretudo, por financiamentos externos, a pesquisa nacional em educação é marcada pela produção de estudos com orientação econômica. Sobre a perspectiva de pesquisa importa destacar:

As soluções apresentadas para os problemas educacionais eram basicamente tecnicistas, visando a eficácia e eficiência na escolarização de uma porção cada vez maior da população. Daí o prestígio dos testes psicológicos, da instrução programada, dos objetivos comportamentais, do planejamento. Nos institutos oficiais de pesquisa eram realizados levantamentos e surveys, buscando a caracterização de professores, alunos e escolas, assim como estudos descritivos de métodos de ensino e recursos didáticos. (ANDRÉ, 2006, p.14). 
Um traço do desenvolvimento da pesquisa em educação, considerando o marco a criação do INEP (1938) até os 1970, é que seu lócus não é a Universidade; seu nascimento é movido pela ação indutora de órgãos governamentais, que se firma nas três primeiras décadas como principal protagonista. Sobre o ostracismo da universidade nesse interregno Aparecida Joly Gouveia (1971, p. 10), em estudo seminal acerca do tema, assevera que "a maior parte dos trabalhos realizados por professores universitários, porém, resulta de esforços individuais relacionados a interesses intelectuais ou acadêmicos". Prossegue lembrando que a "pesquisa é praticamente negligenciada nos orçamentos das universidades e, em geral, desempenha papel secundário na carreira do professor universitário".

Em resumo, a pesquisa na área de educação não nasceu de um movimento da universidade, mas foi induzida pelos órgãos governamentais dentro de expectativas muito definidas: obter subsídios para as políticas educacionais. Este propósito, contudo, parece não ter alçado êxito, uma vez que o estudo de Aparecida Joly Gouveia, antes citado, detectou, como bem sinalizado por André (2006, p. 14), "uma separação total entre o que era pesquisado na área de educação e as medidas governamentais".

O ostracismo da universidade na produção da pesquisa em educação se inverte rapidamente a partir de sua primeira regulamentação - o Parecer Sucupira, (1965). Desde então, a universidade, em particular a formação pós-graduada stricto sensu, assume papel central na produção de conhecimento na área. Com efeito, os anos de 1970 são pródigos para a pósgraduação, assistindo-se um rápido crescimento de sua oferta, bem como é nesse período que ela se configura como "objeto de planejamento estatal", sendo formulado o I PNPG (1975-1979), estabelecendo procedimentos de acompanhamento e avaliação (FERREIRA, 2009).

Desse modo, no interstício de uma década, entre 1965 e 1975, são criados 16 cursos de pós-graduação stricto sensu em educação (ANDRÉ, 2006), contexto institucional que concentra, à época, os recursos humanos com mais alta qualificação no país. A "expansão dos quadros das universidades" e à "emergência de alguns grupos de pesquisa", ao lado da instituição do Departamento de Pesquisas Educacionais (1971) da Fundação Carlos Chagas, é outro importante setor que congrega corpo significativo de pesquisadores responsáveis por impulsionar o desenvolvimento da pesquisa em educação. Investimentos na formação de profissionais da área no exterior contribuem, no seu retorno, para ampliar e reforçar o segmento docente das universidades e programas de pós-graduação, anota Marli André ao sintetizar o que se sucede nesse período, por ela denominado de institucionalização da pesquisa em educação. 
Estas ações, de certo modo, compõem o movimento pelo qual a Universidade se firma definitivamente como lócus da pesquisa em educação, bem como a emergência de alguns centros especializados, momento também marcado por deslocamentos nos objetos e nos métodos da pesquisa. Gatti (2001, p. 67) identificou os novos temas em estudo: currículos; avaliação de programas; caracterização de redes e recursos educativos; relações entre educação e trabalho; características de alunos, famílias e comunidade; nutrição e aprendizagem; validação e crítica de instrumentos de diagnóstico e de avaliação; estratégias de ensino. Esses estudos passaram a ser produzidos a partir do uso de referenciais teóricos mais críticos e de instrumentos quantitativos mais sofisticados de análise. Porém, a autora aponta a permanência de problemas na qualidade dos trabalhos produzidos, como a pulverização de temas, o modismo e a fragilidade metodológica na abordagem e na análise dos problemas.

As duas décadas seguintes (1980 e 1990) registram crescimento expressivo da pesquisa em educação, assim sintetizado por André (2006):

a) Os temas se ampliam e se diversificam (p. 16). Enquanto nas décadas de 1960 e 1970 predominam estudos com ênfase em variáveis de contexto e seu impacto no desempenho dos sujeitos, nos anos 1980 são substituídos pelas investigações de processos. O exame de questões gerais cede, pouco a pouco, lugar "a análises de problemáticas locais, investigadas em seu contexto específico";

b) Os enfoques também se ampliam e se diversificam (p. 16), difundindo-se a metodologia da pesquisa-ação e da teoria do conflito, especialmente no início da década de 1980, em contraponto a orientação tecnicista. Propaga-se o reconhecimento de que a compreensão e a interpretação das questões em torno do fenômeno educacional reclamam "enfoques multi/inter/ transdisciplinares e tratamentos multidimensionais";

c) Ascensão de outras abordagens metodológicas (p. 16), com forte adesão aos estudos qualitativos, cuja heterogeneidade de métodos de produção e de análise de dados é percebida como possibilidade de maior e melhor exploração das questões educacionais.

d) Mudança no contexto de produção dos trabalhos de pesquisa (p. 17) configurada na ênfase no exame de "situações reais do cotidiano da escola e da sala de aula", evidenciando a limitação de análises educacionais baseadas "em situações controladas de experimentação, do tipo laboratório".

O inventário do desenvolvimento da pesquisa em educação nas décadas finais do século passado revela um percurso de avanço progressivo, mas também de críticas contundentes a "questões de teoria e método", conforme alerta Gatti (2001, p. 69), problemas resultante em uma produção de qualidade desigual. Nesse interregno, como assinala a autora, destaca-se também 
a consolidação de grupos de pesquisa que despontam como referência em algumas subáreas, expertise que, conforme anota a autora, encontra em ações científicas e associativas oportunidade de visibilização e fortalecimento. As reuniões nacionais e regionais da Associação Nacional de PósGraduação e Pesquisa em Educação (ANPED) é um desses espaços. Esta entidade, que congrega pesquisadores e programas de pós-graduação stricto sensu em educação do país assume, desde meado dos anos 1970, forte atuação política e acadêmica, promovendo intercâmbio, integrando pesquisadores e difundido o conhecimento produzido na área.

Decorrida quase duas décadas do século XXI, a universidade, em particular a pósgraduação stricto sensu, firma-se como lócus privilegiado da produção da pesquisa em educação no Brasil, momento também em que se acentua o desenvolvimento de processos associativos entre pesquisadores e grupos de pesquisa. Com efeito, a ruptura com o modelo de pesquisa individual demarca, como esclarece o Plano Nacional de Pós-Graduação (PNPG) 2011-2020 (BRASIL, 2010, p.192), "a transição para o modo 2 de produção de conhecimento", no qual a ciência está fortemente articulada aos contextos de aplicação, ou seja, às demandas da sociedade, com maior responsabilidade social, em que os atores envolvidos trabalham de forma colaborativa e negociada." O aglutinamento dos pesquisadores em redes desponta como modelo, caminho para enfrentar os desafios da pesquisa e da produção do conhecimento na contemporaneidade.

Para além das diversas características e terminologias que surgem nas experiências com este desígnio, importa realçar que não se trata apenas de uma nova forma de representação do conhecimento, mas principalmente, de uma mudança epistemológica e teórico-metodológica, uma outra maneira de conceber e produzir conhecimento e se colocar como pesquisador nesse processo, o que requer romper com o isolamento, pesquisar em colaboração e explorar as diversas expertises de cada indivíduo e ou grupo de pesquisa que compõem o conjunto de pesquisadores (FARIAS et al., 2018).

A demanda pela constituição de pesquisas em redes emerge fomentada, sobretudo, por medidas governamentais adotadas no primeiro decênio dos anos 2000, em especial pela definição da Capes como responsável pela formulação de políticas para a formação de professores da Educação Básica (Lei $n^{\circ}$ 11.502/2007). Entre outros aspectos, as ações implementadas nesse momento buscam estabelecer um vínculo mais estreito entre instituições formadoras e escolas públicas, articular graduação e pós-graduação e valorizar o magistério. É na esteira desse movimento, impulsionado também por reivindicações apresentadas em vários encontros de pesquisadores e de grupos interinstitucionais de pesquisa, que o Programa Observatório da Educação (OBEDUC) é lançado em 2006 pela CAPES/INEP. 
Apresentamos, a seguir, um contorno geral de experiência de pesquisa em rede empreendida pela articulação de três grupos de pesquisa consolidados vinculados a quatro programas de pósgraduação em educação, de três universidades públicas situadas nas regiões Nordeste e Sudeste do país, iniciativa apoiada pelo Programa Observatório da Educação (OBEDUC) promovido pela CAPES. Esta iniciativa visa promover, de modo integrado, a produção de conhecimento sobre a Educação Básica e a formação do pesquisador dessa área (BRASIL, 2006). Trata-se de ação com forte potencial indutor de melhoria na formação do professor, tendo como esteio o princípio da aproximação e da interlocução universidade e escola pública.

\section{Delineamentos gerais de uma experiência de pesquisa em rede}

A noção de rede evoca, de acordo com o Dicionário Houaiss da Língua Portuguesa (HOUAISS e VILLAR, 2009, p. 1.627), a ideia de entrelaçamentos, de um "conjunto de pontos que se comunicam entre si" ou de "pessoas, órgãos ou organizações que trabalham em conexão, com um objetivo comum". É sob essa perspectiva que os integrantes do Projeto em Rede OBEDUC $\mathrm{n}^{\mathrm{o}} 20667$ realizaram pesquisa sobre desenvolvimento profissional docente e inovação pedagógica com professores dos Estados do Ceará, Minas Gerais e São Paulo, em três núcleos que sediam as equipes locais. Pesquisa em rede porque assumida como ação de coletivo e de colaboração entre pares desde as decisões teóricas e metodológicas de fundo aos encaminhamentos mais operacionais em torno do objeto de estudo; pesquisa em rede movida pelo interesse de também contribuir para a formação de seus pesquisadores, iniciantes e veteranos (FARIAS, JARDILINO e SILVESTRE, 2017).

Esta compreensão guiou a aproximação de integrantes de três grupos de pesquisa cadastrados no Diretório do CNPq: Educação, Cultura Escolar e Sociedade (EDUCAS), vinculado ao Programa de Pós-Graduação em Educação da Universidade Estadual do Ceará (UECE); Formação e Profissão Docente (FOPROFI), ligado ao Programa de Pós-Graduação em Educação da Universidade Federal de Ouro Preto (UFOP); e, o grupo de estudo e pesquisa Escola Pública, Infâncias e Formação de Professores (GEPEPINFOR), vinculado aos Programas de PósGraduação em Educação e Educação e Saúde na Infância e na Adolescência, da Universidade Federal de São Paulo (UNIFESP-Guarulhos). Em conjunto, no período de 03/2013 a 11/2017, esses pesquisadores desenvolveram investigação, com desenho multicêntrico, com pessoas de contextos institucionais distintos (UECE - Ceará, UFOP - Minas Gerais e UNIFESP - São Paulo) e em momentos de formação diversos (graduandos, especialistas, mestrandos, doutorandos e professores da Educação Básica). 
O percurso metodológico adotada nessa pesquisa em rede tem sua seiva no trabalho colaborativo, aqui compreendido como metodologia utilizada na estruturação e a organização da rede de pesquisa numa perspectiva de decisões compartilhadas, o que se fez mediante a adoção de estratégias de interação e diálogo que favoreçam a manifestação e o posicionamento dos pesquisadores como sujeitos autores da investigação (FARIAS et al., 2018, p. 65).

Seu contorno envolveu a configuração de núcleos, constituídos pelos grupos de pesquisa de cada IES, tendo a infraestrutura desses contextos e dos programas de pós-graduação stricto sensu em Educação envolvidos como base de trabalho. Espaço físico e acadêmico que assegurou condições materiais para a realização das atividades.

Um objeto de estudo em comum, no caso o desenvolvimento profissional docente, é outro elemento definidor da ideia de pesquisa em rede vivenciada pelos pesquisadores integrantes do Projeto OBEDUC n ${ }^{\circ}$ 20667. Seu escopo geral se deteve em analisar aspectos da experiência vivida por professores da Educação Básica do Ceará, Minas Gerais e São Paulo, no âmbito do Programa Institucional de Bolsa de Iniciação à Docência, que contribuem para seu desenvolvimento profissional, desvelando se essa participação é mobilizadora de práticas inovadoras de ensino. Desse modo, o desenho da pesquisa contempla questionamentos acerca do desenvolvimento profissional de professores da Educação Básica que participam do PIBID como supervisores.

Categoria central da pesquisa, o desenvolvimento profissional docente foi compreendido como um processo de aprendizagem, de crescimento mais vivencial e integrador ocorrente ao longo da carreira docente e que pode ser facilitado ou inibido, tendo com principais referências teóricas as formulações de Antônio Nóvoa, Marcelo García, Denise Vaillant, Francisco Imbernón e Júlia Oliveira-Formosinho.

Professores da Educação Básica envolvidos no Pibid como professores supervisores compuseram os sujeitos da pesquisa. O estudo abrangeu 90 docentes, entre ativos e egressos dessa função no Pibid, distribuídos equitativamente entre os três núcleos (30 sujeitos em cada).

O plano geral da investigação condensou três fases: a primeira destinada ao aprofundamento de estudos e mapeamento de dados secundários sobre o tema; a segunda voltada para a produção de dados primário; e, a terceira abrangeu o movimento de análise e interpretação dos dados. Na prática esses momentos envolveram inúmeras ações, todas partilhadas coletivamente, inter e intra núcleos, movimento que exigiu, conforme anotado pelos coordenadores dessa experiência: 
Encontros ampliados de planejamento entre os núcleos, elaboração de agenda anual comum de trabalho, sessões de estudo, debates mediados pelo uso de recursos tecnológicos disponíveis na internet (skype e web conferências), realização de oficinas sobre temas e práticas de pesquisa (a exemplo do uso do software NVIVO), produção de textos e discussão entre núcleos, são algumas das ações que deram forma a dinâmica de desenvolvimento de nossa investigação em rede (FARIAS, JARDILINO e SILVESTRE, 2016, p. 17).

Nesse caminho, inúmeros aprendizados (trabalhar com grupos heterogêneos um desafio constante); conquistas importantes (vários integrantes aprovados em concursos públicos e na pós-graduação, entre estes, professores da escola pública); interfaces férteis no fortalecimento de grupos de pesquisa e de programas de pós-graduação (participação em bancas, ações de solidariedade entre programas de pós-graduação, intercâmbio de docentes e estudantes e estímulo à inserção de professores da escola pública na pós-graduação stricto sensu) e na interlocução universidade/escola pública, bem como na produção de conhecimento em parceria na elaboração de artigos, organização de livros e comunicações visando a participação em eventos.

O Projeto OBEDUC n 20667 envolveu, durante sua vigência, 102 participantes, entre discentes (41 graduandos, 20 mestrandos, 4 doutorandos, 29 professores da Educação Básica e 8 colaboradores), todos logrando êxito na trajetória de formação superior, seja concluindo sua graduação, ingressando na pós-graduação stricto sensu ou defendendo sua tese ou dissertação.

Os aprendizados e indicadores dessa pesquisa em rede, sintetizados na obra "Pesquisa em rede: diálogos de formação em contextos coletivos de conhecimento" (FARIAS et al., 2018), evidenciam que essa é uma alternativa fértil de articulação entre graduação, pós-graduação e Educação Básica e que inverte a lógica da formação de professores, fazendo coro ao argumento de Nilda Alves, manifesto há quase trinta anos atrás, de que é inaceitável a ideia de que a formação de um profissional "se dá, exclusivamente, em cursos de formação (ela se dá em múltiplas esferas". A pesquisa é um dessas esferas ou, como temos dito, "um contexto legítimo de formação, pois o professor, como alguém que lida com o conhecimento e é responsável por mediar o processo de conhecer de outras pessoas, necessita compreender como se conhece" (p. 107).

\section{Contributo das redes na formação de novos pesquisadores em Educação}

Processos associativos de pesquisadores como a experiência de pesquisa em rede detalhada neste texto evidenciam seu potencial na formação de novos pesquisadores, sobretudo na área das Ciências Humanas e Sociais Aplicadas, a exemplo da Educação. Nesse movimento, a pós- 
graduação stricto sensu firma-se definitivamente como lugar do desenvolvimento da produção nesses campos, pois dela provêm o maior volume dos estudos que fazem avançar o conhecimento.

Nesse aspecto, não é demais sublinhar que a formação de recursos humanos com alta qualificação mantém-se, nesses primeiros decênios do século XXI entre os maiores desafios sociais do país. Formar profissionais com capacidade de produzir conhecimento que contribua na formulação, apoio e implementação de políticas em organizações sociais nas mais diferentes áreas do conhecimento é hoje um imperativo. Essa é uma preocupação primeira que não podemos perder de vista enquanto pesquisadores.

Indicadores recentes acerca da formação dos brasileiros revelam situação delicada e inquietante, uma vez que mostram resultados que posicionam o país atrás de todos os países desenvolvidos e de muitos considerados subdesenvolvidos. Hoje no Brasil, de acordo com dados divulgados pelo $\mathrm{PNAD}^{1}$, aproximadamente $8 \%$ da população com 15 anos ou mais não é alfabetizada, isso quer dizer que cerca de 12,9 milhões de pessoas não sabem ler, escrever e nem dominar cálculos, sendo considerados analfabetos. A região Nordeste é a que apresenta maior taxa de analfabetismo (16,2\%), movimento que se mantém nos últimos cinco anos. Amargamos, ainda, uma alta concentração de analfabetos funcionais (17,1\% em 2015), sendo o Nordeste a região que registrou a taxa mais alta (26,6\%). Estamos muito aquém do desempenho de países como a Coréia do Sul e Uruguai (respectivamente, $2 \%$ de analfabetos), Argentina e Cuba (com 3\%), Chile (com 4\%) e México (com 10\% de analfabetos) ${ }^{2}$.

Se olharmos para a escolarização básica, ainda de acordo com dados do PNAD, mais da metade dos brasileiros com 25 anos ou mais não conseguiu completar o Ensino Médio até 2015, o que significa que o percentual de brasileiros adultos que terminam o Ensino Médio situa-se na casa dos $14 \%$, enquanto em países como a Malásia o percentual é de $21 \%$, no Chile $26 \%$ e na Coréia do Sul $62 \%$. Este fato, não só afasta estes jovens da ciência produzida no País, pela não conclusão da escolarização básica, como os impede de acessar os cursos de pós-graduação.

E a Educação Superior? Segundo dados da Organização para a Cooperação e o Desenvolvimento Econômico (OCDE), o Brasil tem apenas 14\% da população adulta (entre 24 e

1 Dados extraídos do endereço: http://www.brasilescola.com/brasil/idh-escolarizacao-no-brasil.htm. Acessado em $14 / 05 / 2012$.

2 Extraído da matéria: "Só 14\% dos adultos no Brasil tinham ensino superior em 2015, nota OCDE”. Disponível em: http://www.valor.com.br/brasil/4710581/so-14-dos-adultos-no-brasil-tinham-ensino-superior-em-2015-nota-ocde. Acessado em 4/03/2018. 
64 anos) com ensino superior completo ${ }^{3}$. A média é consideravelmente menor que a de $35 \%$ dos países da OCDE. O percentual de adultos brasileiros com ensino superior é mais baixo que a média de países latinos como o Chile (21\%), Colômbia (22\%), Costa Rica (23\%) e México (16\%).

E o que dizer da pós-graduação ${ }^{4}$ ? Este segmento, infelizmente, ainda é um território de poucos. O número de alunos matriculados em cursos de mestrado e doutorado não chega a $1 \%$ da população ${ }^{5}$ (apenas 0,51\%). De acordo com dados do $\mathrm{CNE}^{6}$ (2016), "O Brasil tem 122.295 estudantes de pós-graduação, dos quais 76.323 são de mestrado acadêmico, 4.008 de mestrado profissional e 41.964 de doutorado".

É verdade que nos últimos anos temos presenciado um movimento de expansão notável, conforme evidencia o atual documento de área da CAPES (2016) que, ao analisar os últimos períodos de avaliação (desde 2004), identifica movimento significativo de crescimento da oferta nesse campo. O número de cursos de mestrado e doutorado no país, considerando as 48 áreas de conhecimento, praticamente triplicou em 16 anos: se em 2000 havia 1.439 programas disponíveis, em 2016 esse número saltou para 4.257.

A Área de Educação, por sua vez, em setembro de 2016, registrou 246 cursos de pósgraduação, sendo 128 de Mestrado Acadêmico, 74 de Doutorado e 44 de Mestrado Profissional. Tais cursos se organizam em 172 Programas, 74 deles com Mestrado e Doutorado Acadêmicos, 54 com Mestrado Acadêmico e 44 com Mestrado Profissional (MEC/CAPES, 2016, p. 2). Também é expressiva a melhora do conceito dos programas da região Nordeste que atualmente conta com cinco programas com conceito 5 (UFBA, UNEB, UFPE, UFRN, UECE). Mesmo assim, ainda estamos longe de ter um número de doutores proporcional à população ativa, ao PIB e às nossas

3 Informações retiradas do endereço: http://revistaensinosuperior.uol.com.br/textos.asp?codigo=12124. Acessado em $14 / 05 / 12$

4 Veja a matéria: “Analisamos cursos de pós-graduação no Brasil”, disponível em: https://revistagalileu.globo. com/Multimidia/Infograficos/noticia/2015/06/analisamos-os-cursos-de-pos-graduacao-no-brasil2.html. Consultada em 2016.

5 Veja a matéria: "País tem 705 mil mestres e doutores", disponível em: https://www.em.com.br/app/noticia/ especiais/educacao/2013/04/23/internas educacao,375760/pais-tem-705-mil-mestres-e-doutores.shtml. Acessado em 2016.

6 Disponível em: http://portal.mec.gov.br/conselho-nacional-de-educacao/180-estudantes-108009469/pos-graduacao-500454045/2583-sp-2021081601. Acessado em: 04-03-18. 
riquezas naturais ${ }^{7}$, pois para cada mil brasileiros temos somente 1,4 doutores, enquanto na Suíça esse índice é de 23, na Alemanha, 15,4 e, nos Estados Unidos, 8,4.

Esses indicadores, pelos desafios que retratam, ao mesmo tempo evidenciam avanços, nos convocam também a problematizar questões relacionadas às perspectivas da pesquisa no campo da educação, considerando o momento histórico nacional recente que enfrentamos. Que perspectivas vislumbrar para o desenvolvimento da ciência, tecnologia e inovação, em particular para a pesquisa no campo da Educação, em um contexto de austeridade fiscal e de aprofundamento da crise política, agravado por um governo com um projeto neoliberal de nação, sem legitimidade para a consecução de alterações nas políticas públicas e, que, mesmo assim, desenvolve uma agenda de graves restrições aos direitos sociais?

Esta é uma indagação necessária considerando ser a universidade, em particular a universidade pública, lócus privilegiado de desenvolvimento da produção de conhecimento nas mais diversas áreas e, paradoxalmente, nesse contexto de crescentes restrições aos direitos sociais, encontrar-se em risco, ameaçada em todos os âmbitos: político, financeiro e em sua autonomia didático-científica.

Do contrário, como entender o sucateamento da universidade pública? A situação "dramática e aviltante" vivida pela UERJ ${ }^{8}$, pelos professores da UEPG e da UERN, e várias outras instituições espalhadas pelo território brasileiro? O que dizer da demissão ${ }^{9} \mathrm{em}$ massa dos professores com base na reforma trabalhista em curso no atual governo? E do corte de bolsas de estudo e de financiamento de pesquisas por parte das agências públicas? Essas questões não são triviais e não podem ficar alheias ao processo de compreensão da realidade educacional.

Não podemos desconsiderar o movimento em curso de ataque e de desmoralização da universidade, evidenciado de modo emblemático na "Operação, Ouvidos Moucos", que investigou o desvio de recursos da Universidade Aberta na UFSC. Também é sintomático desse risco manifestações recentes do MEC contrárias à livre expressão e circulação de pensamento

7 Veja a matéria: "Presidente da Capes apresenta PNPG 2011-2020 na ABC". Extraído do endereço: http://www. abc.org.br/impressao.php3?id article=1158. Acessado em 14/05/12.

8 "Reitor afirma que situação da Uerj é dramática e aviltante", matéria disponível em: https://g1.globo.com/rio-de-janeiro/noticia/reitor-afirma-que-situacao-da-uerj-e-dramatica-e-aviltante.ghtml. Acessado em 03/03/18.

9 "Estácio anuncia demissão em massa de professores, diz sindicado" - matéria publicada em: https://g1.globo. com/economia/noticia/estacio-promove-demissao-em-massa-de-professores-diz-sindicato.ghtml. Acessado em $03 / 03 / 18$.

p/Ualis salvador, v. 3, n. 1, p. 12-29, jan./abr. 2018 
e de produção de conhecimento, expresso em dois episódios recentes: a Nota do MEC contra a disciplina sobre "O Golpe de 2016 e o Futuro da Democracia no Brasil", ofertada pelo Professor Titular Luís Felipe Miguel, da Universidade de Brasília; e, a acusação policial contra Professor Emérito da UNIFESP de "apologia ao crime" por realizar pesquisas sobre a cannabis sativa (vulgo maconha). Entendemos que a autonomia acadêmica e a liberdade de pesquisa científica são requisitos básicos de uma sociedade democrática (ABA, 2018).

No momento crítico que vivemos a redução drástica do financiamento público na área da Educação, Ciência e Tecnologia desdobra-se como a face visível das medidas polêmicas instituídas pelo atual governo. Aliás, o corte drástico em CT\&I no Orçamento de 2018, aprovado pelo Congresso Nacional em 13 de dezembro de 2017, pode ser notificado como uma "tragédia anunciada" por várias entidades científicas, entre elas a ANPED e ABA, as quais se manifestaram repudiando esse movimento. Para que possamos dimensionar o impacto dessa medida basta dizer que o

[...] "valor aprovado para o orçamento geral do Ministério da Ciência, Tecnologia, Inovações e Comunicações - MCTIC, para 2018, é cerca de $19 \%$ menor do que o que foi aprovado para 2017 pelo mesmo Congresso. O orçamento movimentável, destinado a custeio e investimento (ou seja, excluídas as despesas obrigatórias e a reserva de contingência), é de aproximadamente $\mathrm{R} \$ 4,7$ bilhões para o próximo ano, $25 \%$ a menos do que o aprovado para o orçamento de 2017. (ANPED, 2017).

Ao repudiar tais medidas, a nota pública da Associação Nacional de Pós-Graduação e Pesquisa em Educação adverte ainda para os reflexos desses cortes nas agências de fomento, universidades públicas e instituições de pesquisa, destacando, por exemplo, que:

Os recursos para a CAPES em 2018, uma agência fundamental para a pósgraduação brasileira, responsável por grande parte da pesquisa científica produzida no país, teve uma diminuição de $20 \%$ em relação ao aprovado para o orçamento de 2017. Nas universidades públicas federais, os recursos para custeio foram mantidos em patamar 20\% inferior aos valores de 2014 e os recursos para investimento foram ainda mais reduzidos, representando agora um corte de mais de $80 \%$ em relação a 2014. Muitas instituições de pesquisa importantes para o país, como a Fiocruz, o Ibama e o Inmetro foram igualmente atingidas por cortes de recursos para custeio e investimento. Ademais, quando se considera que os recursos federais para a área são catalizadores importantes de recursos estaduais, por meio das Fundações Estaduais de Amparo à Pesquisa 
- FAPs, que estão sendo também fortemente reduzidos, percebe-se a gravidade do momento para o sistema nacional de CT\&I. (ANPED, 2017).

Não perder de vista esta conjuntura é fundamental para todo pesquisador, seja iniciante ou experiente. Problematizar essas situações é um desafio que se impõe ao campo da produção do conhecimento em todas as áreas, especialmente no campo da Educação. Uma reflexão necessária se quisermos produzir um conhecimento crítico, que contribua para avançarmos na nossa capacidade de compreensão e de intervenção na vida social contemporânea. Mais do que nunca, parece-nos fundamental entender que o conhecimento não é neutro; ele se faz e é produzido implicadamente.

\section{REFERÊNCIAS}

ANGELUCCI, C. B.; KALMUS, J.; PAPARELLI, R.; PATTO, M.H.S. O estado da arte da pesquisa sobre o fracasso escolar (1991-2002): um estudo introdutório. Educação e Pesquisa, vol. $30, n^{\circ} 1$, p. 51-72, 2004.

ALMEIDA, Maria Isabel de. Realidade social e os desafios da pesquisa em Educação: reflexões sobre o nosso percurso. Revista Psicologia da Educação, $\mathrm{n}^{\mathrm{o}}$ 31, agosto, 2010. Disponível em: http://pepsic.bvsalud.org/scielo.php?script=sci_arttext\&pid=S1414-69752010000200005 Acesso em $01 / 03 / 18$.

ANDRÉ, Marli Eliza Dalmazo Afonso. A jovem pesquisa educacional brasileira. Diálogo Educacional, Curitiba, v. 6, n.19, p.11-24, set./dez., 2006.

ANPED. Orçamento de CT\&I para 2018: tragédia anunciada!. Nota pública publicada em 20/12/2017. Disponível em: http://www.anped.org.br/news/orcamento-de-cti-para-2018-tragedia-anunciada. Consultado em: 02-03-18.

ANTÓNIO NÓVOA EXORTA PROFESSORES A DIZER “NÃO”. Matéria publicada em 03/05/2013 - Público e Lusa. Disponível em: http://www.publico.pt/sociedade/noticia/antonio-novoa-exorta-professores-a-dizer-nao-1593260. Acesso em 08.set.2014 
BALBACHEVSKY, Elizabeth. A pós-graduação no Brasil: novos desafios para uma política bem sucedida. In: Os desafios da Educação no Brasil. Rio de Janeiro: Nova Fronteira, 2005, p. 285-314. Disponível em: https://portais.ufg.br/up/67/o/Pos-Graduacao_Brasil_2.pdf. Acesso em 20 de maio de 2016.

BRASIL. MEC. CAPES. Plano Nacional de Pós-Graduação - PNPG 2011-2010. Brasília: Distrito Federal: CAPES, 2010.

Decreto $n^{\circ} 5.803 / 2006$. Institui o Programa Observatório da Educação. Disponível em http://www.capes.gov.br/educacao-basica/observatorio-da-educacao/legislacao Acesso em 21.dez.2017.

. Lei $n^{\circ} 11.502$, de 11 de julho de 2007. Modifica as competências e a estrutura organizacional da fundação Coordenação de Aperfeiçoamento de Pessoal de Nível Superior - CAPES. Disponível em: http://www.planalto.gov.br/ccivil_03/_ato20072010/2007/lei/111502.htm. Acesso em: 26 jan. 2011.

FARIAS, Isabel Maria Sabino de; JARDILINO, José Rubens Lima; SILVESTRE, Magali Aparecida. Desenvolvimento Profissional Docente e Inovação Pedagógica: estudo exploratório sobre contribuições do PIBID. Relatório Final de Pesquisa. Programa Observatório da Educação/OBEDUC. Fortaleza: UECE/PPGE/EDUCAS, 2017. (mímeo).

; __ ; _ _ _ Contribuições do OBEDUC como pesquisa em rede para a formação do professor. Revista Educação Matemática em Foco, vol. 5, nº 1, 2016, p. 13-29.

; ; ; ARAÚJO, Regina Magna Bonifácio. Pesquisa em Rede: diálogos de formação em contexto coletivos de conhecimento. Fortaleza: EdUECE, 2018.

FERREIRA, Liliana Soares. A pesquisa educacional no Brasil: tendências e perspectivas. Contrapontos, vol. 9, n⿳ 1, p. 43-54, Itajaí, jan/abr., 2009.

GATTI, Bernadete Angelina. A construção da Pesquisa em Educação no Brasil. Brasília: Plano Editora, 2002.

. Implicações e perspectivas da pesquisa educacional no Brasil contemporâneo. Cadernos de Pesquisa, $\mathrm{n}^{\circ}$ 113, p. 65-81, jul., 2001. 
GOUVEIA, Aparecida Joly. Pesquisa educacional no Brasil. Cadernos de Pesquisa, $\mathrm{n}^{\circ}$ 1, $\mathrm{p}$. 1-48, 1971.

HOUAISS, Antônio; VILLAR, Mauro de Salles. Dicionário Houaiss da língua portuguesa. Instituto Antônio Houaiss de Lexicografia e Banco de Dados da Língua Portuguesa S/C Ltda. ${ }^{\text {a }}$ ed. Rio de Janeiro: Objetiva, 2009.

MEC. CAPES. Documento de Área - Educação. Brasília: Distrito Federal, 2016, 24p. 